BIOMEDICA

Vol. 5, Nos. 3 y $4-1985$

\title{
PRESENCIA DE CAMPYLOBACTER JEJUNI EN AVES DE CORRAL Y SUS MANIPULADORES
}

\author{
FABIO CARMONA V. *
}

\begin{abstract}
En una granja procesadora de aves en la ciudad de Cali, donde se sacrifican 12.000 animales diarios, se escogío para buscar Campylobacter jejuni una muestra de 120 pollos tomando como base una prevalencia del $80 \%$ y empleando un muestreo sistemático para dar una mayor cobertura teniendo en cuenta que la procedencia de los animales variaba diariamente. El porcentaje de positividad en materia fecal fue de $98.33 \%(118 / 120)$. Con la finalidad de averiguar el grado de higiene empleado en la manipulación de las canales, se frotó la superficie de ellos antes y después de introducirle las vísceras que es sabido van dentro del pollo al llegar al consumidor; se encontró que las canales con vísceras estaban contaminadas en un $18.33 \%(11 / 60)$ mientras que antes de este procedimiento la contaminación tan solo fue del $8.33 \%$ (5/60). También fueron examinadas 62 personas para buscar en ellas el C. jejuni encontrándose en $5(8.06 \%)$ la bacteria. A todas las cepas aisladas se les probó la sensibilidad a la eritromicina usando disco de $15 \mathrm{Ug}$ observándose un $100 \%$ de sensibilidad a la droga.
\end{abstract}

\section{INTRODUCCION}

La infección causada por Campylobacter jejuni se puede presentar en forma de casos aislados y la mayoría de las manifestaciones son autolimitadas; causa dolor abdominal y diarrea de 2 ó 3 días de duración, pero en algunos pacientes los síntomas son más persistentes, por ejemplo, estos pueden presentar una severa enterocolitis que semeja colitis ulcerativa aguada (1), mientras que otros deben ser hospitalizados por presentar un cuadro clínico parecido a una apendicitis o colecistitis (2); en estos pacientes con síntomas severos y persistentes se hace necesario instaurar el tratamiento con eritromicinal También se han registrado casos de peritonitis como complicación de la diálisis contínua peritoneal ambulatoria empleada como terapia en pacientes con falla renal (3). El agente etiológico de la enfermedad es un microorganismo gram negativo ubicado anteriormente en el género
Vibrio, actualmente se ha clasificado como Campylobacter fetus (4) con varias subespecies de las cuales la más importante es la jejuni (5). Está establecido que Campylobacter es importante como agente etiológico de enfermedad entérica en humanos (6). Fue descubierto inicialmente (7) por MacFayden y Stockman en 1913 pero solo en 1957 se realizó el primer estudio de las cepas de origen humano observándose que los aislamientos obtenidos procedían preferencialmente de pacientes con diarrea. En 1972 Dekeyser et al (8) y en 1973 Butzler y Colaboradores (9) cultivaron el microorganismo a partir de muestras de materia fecal usando la técnica de filtración por membrana y encontraron Campylobacter en 5.1\% de niños con diarrea y en $1.3 \%$ de niños que no la presentaban. Sólo en 1977 se lograron mejores resultados cuando Skirrow (10) desarrolló un medio de cultivo selectivo, mediante la incorporación de antimicrobianos que frenaban la proliferación de la

* Profesor Asociado, Departamento de Microbiologia, Facultad de Salud, Universidad del Valle. Cali. 
flora intestinal se lograron porcentajes más altos de aislamientos, encontrando el microorganismo a $7.1 \%$ de los pacientes con diarrea $y$ no en aquellos que no la presentaban.

Desde entonces muchos estudios (11) han confirmado los hallazgos de Butzler y Skirrow y explicado la asociación que existe entre la bacteria y el cuadro clínico. Es claro que la enteritis causada por este germen es una zoonosis. El tracto gastrointestinal de una gran variedad de animales salvajes y domésticos actúa como reservorio de la infección. La bacteria también puede encontrarse en aguas contaminadas desencadenando en ocasiones grandes brotes de enteritis (12). Los animales que se consideran de mayor importancia son las mascotas; las aves de corral son la fuente más frecuente de infección de muchos países (13) y la bacteria se encuentra en la carne que se contamina con la manipulación, aunque en el momento de la venta gran parte de la contaminación ha desaparecido (14); la gente que tiene contacto con los animales o la carne presenta evidencia de una aumentada exposición a la infección (15), aunque en los casos clínicos no se pueda establecer un real contacto con estos animales.

Considerando que Campylobacter jejuni está ganando importancia junto con Salmonella y Shigella como agentes etiológicos de cuadros entéricos y que se han encontrado algunos brotes e infecciones esporádicas asociadas con la ingestión de pollo crudo o mal cocido, se hace necesario averiguar el papel que realmente desempeña el consumo de este alimento en la etiología de las diarreas. Luenchrfeld (16) realizó un estudio en pavos y encontró que de 600 animales todos portaban la bacteria; el análisis de las canales demostró un $\mathbf{9 4 \%}$ de positividad y encontró que la inmersión de ellas en agua clorinada disminuyó solo en un $66 \%$ de la presencia de C. jejuni. En cuanto a los pollos se han encontrado porcentajes que van desde $68-78 \%$ de animales que albergan la bacteria en su intestino (17) siendo más alta que para Salmonella en estas aves. Teniendo en cuenta que el pollo es el alimento de este tipo de mayor consumo en nuestro medio se estudió una muestra representativa de los animales sacrificados en el período comprendido entre noviembre de 1984 y febrero de 1985 para averiguar que porcentaje albergaban la bacteria y cuál era el grado de contaminación de las canales; posteriormente se examinó a los manipuladores. A todas las cepas aisladas se le probó la sensibilidad a la eritromicina, droga de elección en el tratamiento.

\section{MATERIALES Y METODOS}

\section{Grupo de estudio y toma de la muestra}

Tomado como base la alta prevalencia reportada en la literatura que va hasta un $80 \%$ en pollos, se tomó una muestra de 20 por cada lote de 12.000 sacrificados diariamente. Los límites de confianza empleados estaban entre $56.4 \%$ y $94.27 \%$ de prevalencia para los lotes muestreados. Se emplé el muestreo sistemático, durante 16 semanas tomando 20 muestras cada 15 días, en días diferentes hasta completar 120 . Se hizo este tipo de muestreo para aumentar la cobertura pues se supo que cada lote sacrificado diariamente provenía de una granja diferente. De cada animal escogido al azar se tomó el intestino en un recipiente estéril para obtener de él el contenido existente en la región cecal, el cual sirvió para la búsqueda de la bacteria. Simultáneamnete, se escogieron al azar 20 canales en un punto del proceso; ellas se dividieron en 2 grupos para el examen, 10 sin vísceras y 10 después de habérsele introducido las visceras, Estas canales fueron frotadas con un escobillón en varios sitios de la piel, cavidad abdominal y cloaca en varios sentidos, durante 30 segundos cada una. Una vez tomada esta muestra el escobillón se introdujo en un tubo que contenía $5 \mathrm{ml}$. de Campy-thio. El total de canales muestreados fue también de 120.

Terminado el muestreo de los animales se examinó la materia fecal de 62 personas, 3 de ellas personal de oficina y el resto manipuladores directos buscando en ellos $C$. jejuni.

La muestra de materia fecal de los manipuladores se transportó al laboratorio en recipientes estériles sin medio de transporte puesto que se sabe que el microorga- 
nismos conservan la viabilidad hasta por 4 días en promedio, cuando se mantienen en las heces a $25^{\circ} \mathrm{C}$. (18).

\section{Procesamiento de la muestra}

Los medios de cultivo empleados para el aislamiento primario y el transporte del escobillón fueron el Campy-BAP y CampyThio respectivamente.

Campy-BAP: consiste en una preparación utilizando como base el agar Brucella adicionado con sangre de cordero la cual fue empleada al $10 \%$, pues la observación del investigador demostró que el medio se contamina menos con sangre a esta concentración que con la aconsejada al 5\%. Los inhibidores incorporados al medio fueron: vancomicina $10 \mathrm{mg}$, trimetoprim $5 \mathrm{mg}$; sulfato de polimixina $2500 \mathrm{U}$, anfotericina B 2 mg y cefalotina $15 \mathrm{mg}$ para cada litro de medio de cultivo.

Campy-thio: es un medio líquido que consiste en caldo tioglicolato, agar al $0.16 \%$ y los inhibidores empleados para el medio sólido (19).

Una vez extraido el cuntenido cecal del intestino se hizo una suspensión en solución salina peptonada con la finalidad de emulsionar el material. De éste se tomaron 3 gotas que se depositaron sobre la superficie del Campy-BAP y se realizó la siembra con el asa bacteriológica. La incubación se llevó a $42^{\circ} \mathrm{C}$ en un frasco al cual se le introdujo un sobre generador de $\mathrm{CO}_{2}$. Las heces de los manipuladores fueron procesadas de la misma forma.

La muestra de las canales, la cual fue transportada en caldo Campy-thio se sembró directamente en el agar con posterior incubación a $42^{\circ} \mathrm{C}$ en atmósfera del $10 \%$ de CO2 empleando el sobre generador.

\section{Identificación}

Las colonias de C. jejuni son no hemolíticas, pueden ser planas, grisáceas con borde irregular o levantado, de apariencia mucosa, miden de 1 a $2 \mathrm{~mm}$. de diámetro y frecuentemente se encuentran diseminados a lo largo de la estria de la siembra. En medios recién preparados, la humedad facilita este crecimiento. A medida que el medio de cultivo envejece se observan colonias aisladas, Al Gram se observaron formas típicas de coma, gram negativas y en algunas preparaciones en forma de " $\mathrm{S}$ ". La prueba de oxidasa y catalasa son positivas. Con estas características se hace la identificación presuntiva. Para realizar la confirmación, las bacterias fueron sometidas a las siguientes pruebas bioquímicas:

a) Sensibilidad al ácido nalidixico usando disco de $30 \mathrm{Ug}$.

b) Resistencia a cefalotina con disco de $30 \mathrm{Ug}$.

c) Incapacidad para crecer a $25^{\circ} \mathrm{C}$ y en presencia de $\mathrm{NaCl}$ al $3.5 \%$.

d) Capacidad para crecer a $42^{\circ} \mathrm{C}$ y $35^{\circ} \mathrm{C}$ y en medio con glicina al $1 \%$.

e) Reducción de nitratos: negativa.

f) Hidrólisis del hipurato de sodio: positiva.

\section{RESULTADOS}

Tomando una muestra representativa de 120 pollos de los sacrificados en una planta procesadora de aves en la ciudad de Cali, se examinó el contenido intestinal encontrándose Campylobacter jejuni en el $98.33 \%$ $(118 / 120)$ de ellos.

Con la finalidad de observar la eficacia del proceso de sacrificio y empaque del pollo se examinaron las canales buscando contaminación por $C$. jejuni (Tabla 1); se encontró que antes de contener las vísceras el $8.33 \%$ $(5 / 60)$ portaban la bacteria y al introducírseles las vísceras en su cavidad abdominal, proceso que se realiza en todas las plantas procesadoras, la contaminación ascendió al $18.33 \%(11 / 60)$. La contaminación total de las canales con y sin visceras fue del $13.33 \%$ $(16 / 120)$.

En la búsqueda de la bacteria en los manipuladores, fueron examinadas 62 
TABLA NN I

Presencia de Cempylobacter iejuni

en canales de pollos

\begin{tabular}{|l|c|c|c|}
\hline & SV & CV & TOTAL \\
\hline Número de canales & 60 & 60 & 120 \\
\hline Número de positivos & 5 & 11 & 16 \\
\hline Porcentajes & 8.33 & 18.33 & 13.33 \\
\hline
\end{tabular}

SV: Canales sin visceras

CV: Canales después de introducir las visceras

personas, 32 mujeres y 30 hombres, 59 tenían contacto directo con los animales y los 3 restantes personal de oficina; se encontró que el 8.06\% (5/62) albergaban la bacteria en su intestino, la distribución por sexo mostró que de los 5 portadores 3 eran mujeres y 2 hombres.

A todas las cepas se les practicó prueba de sensibilidad a la eritromicina, empleando disco de 15 Ug de concentración, encontrándose una sensibilidad del $100 \%$ a la droga, tanto en las cepas de origen animal, como en las de origen humano.

La observación de las colonias mostró pigmentos que podían ir desde el grisáceo hasta la coloración parda en el agar para Campylobacter; en Mueller Hinton, medio donde se probó la sensibilidad al ácido nalidixico, cefalotina y eritromicina, algunas cepas presentaban color grisáceo y hasta amarillento. Al examen directo se observó que predominaba la bacteria en forma de coma, pero en algunos cultivos realizados a $37^{\circ} \mathrm{C}$ se observaban frecuentemente formas espiraladas y en los cultivos de más de 4 días de incubación predominaban las formas cocoides. Todas las 139 cepas aisladas fueron oxidasa y catalasa positivas, pruebas que se realizaron en el agar Mueller Hinton, cumplieron además con las siguientes pruebas bioquímicas que permitieron su clasificación como Campylobacter jejuni: capacidad para crecer en Campy BAP a $42^{\circ} \mathrm{C}$ y $37^{\circ} \mathrm{C}$ ausencia de crecimiento a $25^{\circ} \mathrm{C}$ y en medios que contienen $\mathrm{NaCl}$ al $3.5 \%$, crecimiento en medios que contienen glicina al 1\%; sensibilidad al ácido nalidixico y eritromicina empleando discos de $30 \mathrm{Ug}$ y 15 Ug respectivamente, resistencia a la cefalotina con disco de $30 \mathrm{Ug}$, reducción de nitratos negativa, e hidrólisis del hipurato positiva.

Es necesario anotar que en el aislamiento primario solo se le dió importancia a las colonias cuyo aspecto era compatible con bacterias del género Campylobacter. Por tratarse de un microorganismo relativamente desconocido en nuestro medio, enviamos algunas cepas al CDC en Atlanta donde nos corroboraron que efectivamente nuestros aislamientos correspondían a $C$. jejuni.

\section{DISCUSION}

De igual manera que ocurre con otros patógenos intestinales las infecciones por $C$. jejuni pueden transcurrir sin síntomas, en los portadores sanos, o por el contrario presentar sintomatologías que van desde leves hasta severas. El cuadro clínico varía con la edad y el período de incubación fluctúa entre 1 y 10 días, con un promedio de 3 a 5 días. El $66 \%$ de los pacientes adultos presentan un prodromos de fiebre alta, $\left(40^{\circ} \mathrm{C}\right)$ malestar general, mialgias y dolor de espalda que dura aproximadamente 24 horas y es seguido de náuseas, vómito y dolor abdominal, localizado inicialmente en el área periumbilical, para ser referido posteriormente a las fosas ilíacas. Al día siguiente empieza el cuadro entérico con diarrea acuosa, mal oliente y en algunos casos con sangre; la duración de la diarrea puede ser de 3 a 5 días pero el dolor abdominal persiste más tiempo, es acentuado por la ingestión de alimentos y mejora con la evacuación. La recuperación ocurre en menos de una semana, pero hasta un $20 \%$ de los pacientes pueden presentar recaidas o desarrollar una enfermedad severa en la cual persiste la fiebre y las diarreas sanguinolentas. En los niños la enfermedad es menos severa y el cuadro clínico varía con la edad del paciente. El 90 de los niños presentan sangre en las heces entre el $2^{\circ}$. y $4^{\circ}$. día de la enfermedad (20). Karmali observó que todos los niños mayores de 3 meses de edad presentaban fiebre alta, 


\section{FABIO CARMONA V.}

$\left(40.5^{\circ}\right)$ mientras que los menores de 3 meses permanecían afebriles. La fiebre generalmente desaparece al cuarto día. La diarrea varió en frecuencia e evacuaciones que iban desde 1 ó 2 hasta 20 pero no se presentó deshidratación $(21,22)$. Sólo el $60 \%$ presentaron dolor abdominal, pero en niños mayores de 2 años aumentó hasta un $95 \%$. El $30 \%$ de los pacientes de este estudio tuvieron vómito, el recuento de leucocitos varió desde el normal hasta muy elevado y la velocidad de sedimentación fue de 70 $\mathrm{mm} /$ hora o más (23).

Campylobacter jejuni se puede encontrar en todo tipo de persona independiente de la edad y sexo, existen datos, aunque estos han sido obtenidos por cultivos realizados a pacientes con diarrea (22). Estos datos parecen demostrar que en países en desarrollo la mayor incidencia de infección ocurre en niños menores de 5 años (24), mientras que en otras poblaciones el mayor número se encuentra en las personas de 5-34 años (22), observándose una proporción de 3:2 de hombres a mujeres hasta los 14 años, edad a partir de la cual la proporción se mantiene 1:1 hasta los 54 años, con un aumento en la frecuencia en mujeres mayores de 55 años. En el presente estudio donde se obtuvo una prevalencia de $8.06 \%$ $(5 / 62)$, la proporción continúa $1: 1$, las edades fluctuaron entre 18 y 45 años, de las 62 personas examinadas 32 fueron mujeres y el examen se practicó independiente de si había diarrea o no, aunque en el laboratorio se observaron varias heces fecales de consistencia blanda y aún similíquida. Aunque no es muy clara en la epidemiología de la enfermedad la forma de adquisición, se ha postulado que existen varios medios de exposición al C. jejuni incluyendo contactos animales, productos de ellos, consumo de alimentos crudos o deficientemente cocidos, leche $\sin$ pasteurizar $(25,26)$, agua no tratada (27) y contacto con personas con diarrea $(28,29)$.

De estos factores de riesgo vale la pena resaltar la presencia de la bacteria en el contenido intestinal de pollos y otras aves que ascienden a porcentajes hasta del $78 \%$ (17); en nuestro estudio el examen del contenido intestinal reveló la presencia del
C. jejuni en el $98.33 \%$ de los pollos estudiados, lo cual esta de acuerdo con datos informados por otros investigadores. Esta situación reviste especial importancia por la posibilidad que tienen las canales de ser contaminadas a partir de la flora intestinal haciendo que este alimento sirva como vehículo para transportar el microorganismo al consumidor. La mayoría de las aves vendidas comercialmente tienen Campylobacter como flora intestinal y esta bacteria se establece muy al comienzo de la vida por infección adquirida de las aves más viejas, alimento o agua contaminada; la infección usualmente transcurre sin síntomas y se establece el estado de portador, aún durante toda la vida. Durante el proceso de sacrificio el C. jejunise disemina a las canales (30). En los Estados Unidos la mayoría de las canales vendidas están contaminadas con $C$. jejuni (17) en porcentajes que ascienden al $100 \%$ aún después de congelación (30). En nuestro estudio se trataba de averiguar en que punto se presentaba la contaminación encontrándose que las canales portaban la bacteria en un $8.33 \%(6 / 600)$ porcentaje bastante bajo comparado con los informados en otros países y aumentó tan solo al $18.33 \%$ cuando se introdujo en las canales la bolsa que contiene las vísceras. Aunque el número de canales muestreadas fue relativamente bajo (120 en total), se observa que nuestro medio está aplicando una buena tecnología y estamos en mejores condiciones que otros países considerados como desarrollados, puesto que la contaminación global de las canales (con y sin vísceras) solo es del $13.33 \%(16 / 120)$.

La técnica y el medio de cultivo empleados (Agar Brucella con antibióticos y sangre al $10 \%$ ) han mostrado ser efectivos para aislar Campylobacter, aún de canales refrigerados. Esto fue observado en un estudio realizado comparándolos con otros 6 caldos de enriquecimiento selectivo y por siembra directa en agar (31), indicándonos que los resultados obtenidos son confiables.

La presencia del $C$ jejuni en las canales reviste especial importancia puesto que ya se ha podido establecer la asociación entre enteritis y el consumo de pollos deficientemente preparados, en Barbacoa o por 
"foundue" que consiste en introducir el pollo en aceite caliente durante unos segundos. Istre (32) encontró, en un estudio realizado en Colorado que 11 de 15 miembros de una familia que asistieron a una fiesta desarrollaron síntomas 4 días después, se aisló la bacteria en 2 de los enfermos y de 8 de 10 examinados tenían anticuerpos (IgM) detectables por IFI en título mayor o igual a 32. Estos anticuerpos alcanzaron un máximo nivel dentro de las 3 semanas siguientes con disminución de los tres meses, indicando que efectivamente hubo infección activa. Los estudios epidemiológicos mostraron que el alimento común fue el pollo y lo consumieron en gran cantidad tanto la piel, como otras porciones que ellos describieron como crudas.

Se sabe que el pollo crudo puede albergar la bacteria y que un proceso adecuado de cocción o asado destruye el germen, pero existe la posibilidad de contaminación de otros alimentos que no son calentados, tales como la salsa y ensaladas que se sirven con el pollo, pero indudablemente el microorganismo llegó en este alimento. Con la finalidad de minimizar el riesgo de adquirir enfermedad por consumo de pollos se sugiere una larga cocción. Severin (33) define como larga cocción al horneado y asado por rotación y corta a la barbacoa y "Foundue".

Como objetivo final del estudio se probó la sensibilidad del $C$. jejuni a la eritromicina empleando disco de sensibilidad de $15 \mathrm{Ug}$ observándose que las 5 cepas de origen humano y las 134 animal mostraron un $100 \%$ de sensibilidad a la droga: contrasta este hallazgo con estudios realizados por Blaser en 1981 donde encuentra porcentajes de resistencia del $8 \%$ y $1 \%$ en Suecia y Canadá respectivamente. Es probable que en nuestro medio haya todacía cepas resistentes a la eritromicina, puesto que esta droga no está incluida en la terapia de los cuadros entéricos y no se ha ejercido sobre la bacteria la presión selectiva de los antibióticos.

Finalmente, es necesario anotar que el medio de cultivo empleado fue el agar Brucella adicionado con sangre de cordero al $10 \%$ y los inhibidores vancomicina, trimetoprim, sulfato B de polimxina, anfotericina B y cefalotina; se escogió esta concentración de sangre porque después de hacer varios ensayos utilizándola al 5\%, 6\%, 8\% y $10 \%$ se encontró que el medio era más selectivo y frenaba más el crecimiento de la flora intestinal.

\section{SUMMARY}

In order to have some information about the frecuency of isolation of $C$. jejuni from chickens and handlers, a study was designed. The inform presented hereby show the results from a chicken-processing factory located in the city of Cali (Colombia)

A total number of 120 chikens were screened for C. jejuni. C. jenuni was isolated from 118 out of 120 stool samples from an equal number of chickens $(98,33 \%)$; from 5 out of 60 chickens bodies once they were opened and eviscerated $(8,33 \%)$ and from 11 out of 60 after the visceras were back again into their bodies $(18,33 \%)$. Samples from 62 peoples from the factory were studied for C. jejuni, a positive isolation was found in 5 out of $62(8,06 \%)$. All strain were sensitive to eritromycin as showed by the in vitro sensitivity test.

\section{AGRADECIMIENTOS}

Al Doctor Alberto Alzate, Jefe del Departamento de Microbiología por la asesoría en el cálculo del tamaño de la muestra y el procesamiento de resultados.

A las directivas y personal que labora en la planta procesadora de pollos por permitir la realización de este trabajo y la colaboración prestada en la toma de las muestras.

Al señor Fernando Sierra, Técnico de Laboratorio del Departamento de Microbiología por su valiosa ayuda.

Al Comité de Investigaciones de la Universidad del valle y al ICFES por haber hecho posible la realización del proyectos con su aporte económico. 


\section{LISTA DE SIMBOLOS, NOMENCLATURA UTILIZADA Y OBSERVACIONES}

a) Campy-thio: Tioglicolato con $0.16 \%$ de agar y antimicrobianos.

b) Campy-BAP: Agar Brucella, 10\% de sangre de cordero y antimicrobianos.

c) Campylobacter jejuni: Campylobacter fetus subespecie jejuni.

d) EDA: Enfermedad Diarréica Aguda.

e) Canales: se designa así al pollo después de sacrificado y desplumado.

\section{BIBLIOGRAFIA}

1. Lambert, M.E., Achofield, P,F., Ironside, A.G., Mendel, B.K. Campylobacter colitis. Br. Med. J. 1979. 1: 857-859.

2. Ponka, A., Pitkanen, T., Kosunen, T.U. Campylobacter enteritis mimicking abdominal emergency. Acta Chir Scand. 1981. 147: 663-66.

3. Pepersack, F., O. haene, M., Toussant, Ch. and Schoutens, E. C. jejuniperitonitis complicating continuous ambulatory Peritoneal Dialysis. J. of Clinical Microb. 1982. 16 (4): 739-741.

4. Véron, M. and R. Chatelain. Taxonomic study of the genus Campylobacter Sebald and Véron and designation of the neotype Species Campylobacter fetus (Smith and Taylor) Sebald and Véron. Ins. J. Syst. Bacterilogy 1973. 23: 122-134.

5. Smilbert, R.M. 1974. Genus II. Campylobacter Sabald and Véron 1963, 907 p. 207-211 in R.F. Buchanan and N.I. Gibbons (ed) Bergey's manual of determinative bacteriology, 8th ed. The Williams and Wilkins Co. Baltimore.

6. Billigham, J.D. Campylobacter enteritis in the Gambia. Transactions of the Royal Society of Tropical Medicine and Hygiene. 1981. 75 (5): 641-644.

7. King, E.O. Human infection with Vibrio fetus and a closely related Vibrio. J. Infectious Disease. 1957. 101: 119-128.

8. Dekeyser, P.M., Goswim-Detrain, Butzler, J.P. and Sternon J. Acute enteritis due to related vibrio: first positive stool cultures. J. Infectious Disease. 1972. 125: 390-392.
9. Butzler, J.P., Dekeyser, P. Detrain, M. and Dehaen, F. Related vibrios in stools. Journal of Pediatrics. 1973. 82: 493.

10. Skirrow, M.B. Campylobacter enteritis a "new disease. British Medical Journal 1977. ii: 9-11.

11. Karmali, M.A. and Fleming, P.C. Campylobacter enteritis Canadian. Medical Association Journal 1979. 102: 1525-1592.

12. Mentzing, L.O. Water borne outbreaks of Campylobacter enteritis in central sewden. Lancet. 1981. ii: $352-54$.

13. Simmons, N.A., Gibbs, F.J. Campylobacter sp. in oven ready poultry. J. Infection. 1979. 1: 159-62.

14. Turnbull, P.C., Rose. Campylobacter jejuni and Salmonella in Raw red meats. J. Hyg. Camb. 1982. 88: 29-37.

15. Jones, D.M., Robinson, D.A. Complement fixing antibody to Campylobacter jejuni in poultry and meat process workers. Lancet 1981. i: 440 .

16. Luechtefeld, NW. and Wang, W.L.L. Campylobacter fetus subsp. jejuni in a Turkey Processing Plant. J. of Clinical Microb. 1981. 13 (2) : 266-268.

17. Grant, I.H., Richardson, N.J. and Bokkenheuser, V.D. Broiler chickens as potential source of Campulobacter infections in humans. Journal of Clinical Microb. 1980. 11 (5) : 508-510.

18. Luechtefeld, N.W. Wang L.L., Blaser, M.J. and Reller, L.B. Evaluation of transport and storage Techniques for isolation of Campylobacter fetus subsp jejuni from Turkey cecal specimen. Journal of Clinical Microbiology. 1981. 13: 438-443.

19. Blase, M.J., Berkowitz, I.D., LaForce, F.M., Cravens, J., Relelr, L.B., and Wang, W.L.L. Campylobacter enteritis: clinical and epidemiological features. Ann. Intern. Med. 1979. 91: 179-185.

20. Rivera, J.G., Rodríguez, J.R., Gorbea, H.F., Colón M. y Ramírez-Ronda, Ch. La enteritis por Campylobacter fetus. Bol. Asoc. Med. P. Rico. 1985. 77: 11-14.

21. Karmali, M.A., Fleming P.C. Campylobacter fetus enteritis in children. Journal Pediatrics. 1979. 94 : 527-533. 
22. Butzler J.P., Skirrow M.B. Campylobacter enteritis Clinics in Gastrroenterology. 1979. 8: 737-765.

23. Campylobacter enteritis. Editorial Lancet. 1978. 2 (808) : 135-136.

24. Blaser M.S., Reller L.B. Campylobacter enteritis. M. Engel Jour Med. 1981. 305: 1444-1452.

25. Potter, M.E., Blaser M.S., Sikes, R.K., Kaufman, A.F. and Wells. Hukan Campylobacter infection associated with certified raw milk. American Journal of Epidemiology. 1983. 117-483.

27. Robinson, D.A. Jones, D.M. Milk-borne Campylobacter infection. Br. Med. Journ. 1981 282: 1374-1376.

27. Mentzing, L.O. Waterborne outbreaks of Campylobacter enteritis in central Sweden. Lancet. 1981. 2: 352-354.

28. Doyle, M.P. Campylobacter fetus sub. jejuni and old pathogen of new concern. J. Food Prot. 1981. 44: 480-8.
29. Blaser, M.J., La Force, F.M., Wilson, N.A. et al. Reservoirs of human Campylobacteriosis. J. Infectious Diseases. 1980. 141: 665-9.

30. Blaser, M.J., Taylor, D.N. and Feldman, R.G. Epidemiology of Campylobacter jejuni infections. Epidemiologic Reviews. 1983. 5: 157-176.

31. Beuchat, L.R. Efficacy of Media and methods for detecting and enumerating Campylobacter jejuni in refrigerated chicken meat. Applied and environmental Microbiology. 1985. 50: 934-939.

32. Istre, G.R., Blase, M.J., Shillam, P. and Hopkins, R.S. Campylobacter enteritis associated with undercooked Barbecued chicken. Am. Journ. Pub. Helath. 1984. 74: 1265-1267.

33. Severin, W.P.J. Epidemiology of Campylobacter infecrion in: Newell DG (ed) Campylobacter. Epidemiology Pathogenesis and Biochemistry Lancaster: MTP Press, 1982, pp 285-287. 